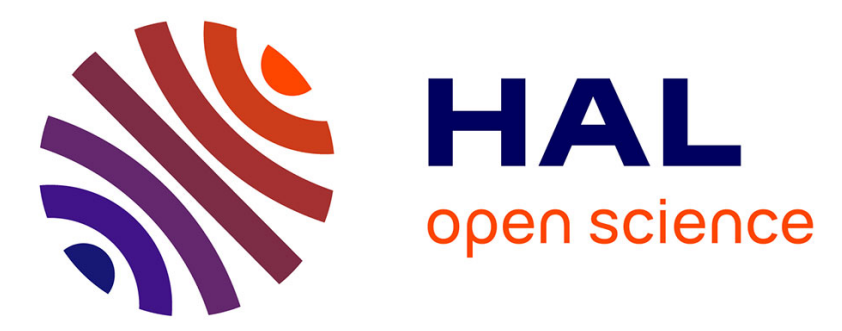

\title{
Application of Information Technology on Traceability System for Agro-Food Quality and Safety
}

\author{
Xue Xia, Yun Qiu, Lin Hu, Guomin Zhou
}

\section{To cite this version:}

Xue Xia, Yun Qiu, Lin Hu, Guomin Zhou. Application of Information Technology on Traceability System for Agro-Food Quality and Safety. 8th International Conference on Computer and Computing Technologies in Agriculture (CCTA), Sep 2014, Beijing, China. pp.257-269, 10.1007/978-3-319-196206_32. hal-01420242

\section{HAL Id: hal-01420242 \\ https://hal.inria.fr/hal-01420242}

Submitted on 20 Dec 2016

HAL is a multi-disciplinary open access archive for the deposit and dissemination of scientific research documents, whether they are published or not. The documents may come from teaching and research institutions in France or abroad, or from public or private research centers.
L'archive ouverte pluridisciplinaire HAL, est destinée au dépôt et à la diffusion de documents scientifiques de niveau recherche, publiés ou non, émanant des établissements d'enseignement et de recherche français ou étrangers, des laboratoires publics ou privés. 


\title{
Application of Information Technology on Traceability System for Agro-food Quality and Safety
}

\author{
Xue Xia, Yun Qiu, Lin Hu, Guomin Zhou \\ Agricultural Information Institute (AII) of the Chinese Academy of Agricultural Sciences (CAAS), Beijing \\ 100081, China
}

\begin{abstract}
In the near past, the increasing demand of produce supply and the frequent foodborne disease have turned the issue of agro-food quality and safety into the key point of concerned all over the world. The approach of agro-food traceability is being under the exploration in lots of communities in the world for controlling the occurrence of quality and safety accidents, restoring consumer confidence. In this paper, we first introduce the implication of the traceability system for agro-food quality and safety, and the development situation of the system in China and overseas have been described. Then, the application of information techniques for agro-food traceability has been elaborated base on the summary of key techniques in recent produce traceability. At last, the existence problem in the construction of traceability system for agro-food quality and safety is pointed out so as to provide a reference to optimize and improve the traceability system of produce quality and safety.
\end{abstract}

Key words: Traceability System; Information Technology; Agro-Food; Quality and Safety

\section{Introduction}

Since the inception of the new century, quality and safety incidents of agro-food were frequently exposed both in China and abroad. Many foodborne diseases caused by agricultural products are emerging in an endless (as shown in Table 1 and Table 2).

These agro-food safety incidents not only cause a great loss to the customer and the country, but led to national consumption panic. There is a certain worrying from the consumers for agro-food safety. Meanwhile, constant exposure of agro-food safety issues attracts extensive attention socially as well.

Achieving traceability for the Agro-food is an irresistible trend of developing agriculture in the world. The establishment of the traceability system has become an important direction for the world's agricultural development. This article mainly introduces the development of the traceability system for the agro-food safety, and focused on the research and application of the information technology in the traceability system for agro-food safety.

Table.1 The quality and safety incidents of agro-food in abroad over the years

\begin{tabular}{lll}
\hline Year & Country & \multicolumn{1}{c}{ Incidents } \\
\hline 2006 & United Kingdom & Cadburys' contaminated chocolate events led to 42 people poisoning \\
2008 & Canada & The listeria infection events cause 23 people death \\
2009 & United States & The tainted peanut butter events sickens 636 people \\
2011 & Germany & The poison cucumbers events give rise to at least 16 people death \\
2012 & Japan & The raw meats poisoning events cause at lowest 4 people death \\
\hline
\end{tabular}


Table.2 The quality and safety incidents of agro-food in China over the years

\begin{tabular}{cl}
\hline Year & \multicolumn{1}{c}{ Incidents } \\
\hline 2003 & The ham dichlorvos events brought negative influences on society \\
2006 & The clenobuterol hydrochloride poison events sickened 336 people in Shanghai \\
2008 & The melamine milk events sickened hundreds of thousands of children \\
2011 & The Shanghai "lean" events undermine the whole meat industry in China \\
2013 & The dead pig floating events in Shanghai influences domestic pork consumption \\
\hline
\end{tabular}

\section{Implication of the Traceability System for Agro-Food}

So far, there is no uniform recognition on the concept of food traceability in the world. The definition of food traceability given by International Standard Organization (ISO) is the capacity that can trace the produce in terms of the history, the usage and the location by using the recorded markers. The Codex Alimentarius Commission (CAC) defines the traceability as the ability of food tracing at every designated section in the producing, processing and circulating. According to the EU General Food Law (Regulation 178/2002), the definition of traceability is the ability to trace and follow a food, feed, food-producing animal or substance intended to be, or expected to be incorporated into a food or feed, through all stages of production, processing and distribution[1].

The traceability system for agro-food safety can be defined as a continuous guarantee system for information stream in production, processing and circulation of agricultural products. In other words, it is a quality safeguard system to record and save related information of agricultural products in their entire supply chain [2]. This traceability system aimed at strengthening information transmission of the produce safety, preventing foodborne hazards and protecting consumers' interests.

\section{Present Development and Conditions of the Agro-Food Traceability System}

\subsection{Present Development and Conditions in Overseas Agro-Food Traceability System}

European Union (EU) is the first place to research and apply the agro-food traceability. A series of agro-food safety accidents in Denmark and Scotland make EU pay more attention to the safety of food and produce. In January 2000, the EU Council released "White Paper on food Safety" in which emphasized the responsibilities of food enterprises for food quality and safety. Moreover, The Hazard Analysis and Critical Control Point (HACCP) has introduced as a safe manufacture practice. In January 2001, EU officially enacted the law no.178/2002, which stipulate the produce companies and food companies must provide relevant measures and data so that the food safety and traceability can be ensured in the whole supply chain [3-5]. In 2006, EU implemented new legislation- EU legislation for food and feed hygiene. It involves the entire food supply chain, and implemented the whole seamless connection from the production of raw material, the launch of ready-for-sale to the customer service of the produce quality and safety [6]. The Seventh Framework Programme (FP7) has been launched by $\mathrm{EU}$ in 2007, which requires establishing the Good Traceability Practice, designing the extensible markup language for produce and food traceability- TraceCoreXML, and the specification of GS1, EPC, RFID, E-barcode label [7].

In the United States, the agro-food traceability system can be divided into three parts: the traceability system for agricultural production; the traceability system for packaging and processing; the traceability system for circulation and sales process [8]. The tracing objects are mainly livestock products. The Public Health Security and Bioterrorism Preparedness Response Act (PHSBPRA) had issued by the US government in 2002. It clearly specifies that the government 
intend to exercise mandatory management for the food safety, and request food firms to build up the relevant records of the whole distribution process [9]. In 2009, the US government passed the Food Safety Enhancement Act in which the U.S. Department of Agriculture was required to establish the food traceability system and develop new traceability technologies and techniques. The integrated family tree of food traceability could be established by means of the linked traceability record from production to distribution. In January 2011, the US government released the Food Safety Modernization Act (FSMA) which specified the food traceability. The act required the high risk food enterprises retaining the record in terms of production, storage and transportation in order to trace the destination and prevent the food security crisis caused by various issues [10].

In Japan, the establishment of the agro-food traceability system synchronizes with the improvement of the produce-related laws, and the established institution of food traceability was early begun to explore. In 2002, seven major institutions, backed by the Ministry of Agriculture, Forestry and Fisheries of Japan, set out to develop the food traceability system. The system record and pass relevant food information in production, processing and circulation with the Internet technology, the barcode technology and the sensor technology. In April 2003, the Japanese government released the Guide for Food Traceability System on the basis of continuous improvement of the laws and regulation relation to food safety. After that, it became a mainstay for enterprises to establish food traceability system. In May 2003, the Food Safety Basic Law was implemented in Japan. The law presented that the research should be launched gradually in both technical and economic perspectives, and comprehensively advances the whole process traceability system from the food production to the market circulation. In 2009, the Japanese government released the Rice Traceability Law, which requested domestic rice production companies, processing companies and distributors have to keep the rice trading records while providing the origin information of rice and batcher [11].

\subsection{Present Development and Conditions of Agro-Food Traceability System in China}

The Chinese government payed great attention to the research and application of the traceability technology for agro-food, and a series of laws and regulations had been enacted to manage and regulate the produce market. In 2002, The Ministry of Agriculture released the Animal immunity marking rules, which stipulated that the animal of compulsory immunization such as pigs, cattle and sheep should equipped immune ear tags and set up the immune-managed file. In December 2007, No. 11 Decree of the Ministry of Agriculture published the Measures for the Management of geographical symbol of agricultural products. Its implementation means geographical origin traceability of produce based on location was possible. At the same time, Beijing launched the capital food safety traceability system of the Olympic Games in order to ensure the food safety. In 2009, the Ministry of Agriculture published the General Principles of Operation Rules for Produce Quality and Safety, which formulated seven operating standards for food safety tracing covered fruits, grains, tea, meats, vegetable and flours. There were fully demonstrated the request in this standards that production recordable, logging query able and quality traceable [12]. In October 2011, the Ministry of Commerce issued the Construction Guidance of the Traceability System for Facilitating the Circulation of Meets and Vegetable during the 12th Five-Year-Plan Period. The guidance claimed that to accelerate the construction of the impeccable traceability system for meets and vegetable and explored the thorough management model and implements the function for fast tracking so as to boost the construction of the city traceability system [13].

\section{Key Technologies in Tracing the Quality and Safety of Agro-Food}




\subsection{Marking and Identification Technology}

At present, the common data carrier technologies in marking system are Barcode technology and Radio Frequency Identification (RFID) technology. The Barcode can be divided into one-dimension barcode and quick response (QR) barcode. The one-dimension barcode coding produce feature information as a code by using a series of letters and numbers, and obtain the produce information from the Internet through read those codes [14]. The quick response barcode can save information by use of the two-dimensional space with better abilities of disturbance and correction and stronger information capacity and density, which can be serving for the purpose of marking and coding for a large number of products [15].

The RFID technology is an automatic identifying technology with contactless mode. The basic RFID system is composed of the electronic tags, the readers and the antennas. The RFID system transport information by using the space coupling of radio wave and the entity objects attributes can be identified with that information [16]. The RFID technology has a series of advantages which are handy information reading and writing, longer reading distance, higher precision, and less susceptible to the effects of harsh conditions.

\subsection{Environmental Factors Surveillance Technology}

The well growing of crops relies on an appropriate growth environment. Environmental factors, such as air temperature and humidity, soil temperature and moisture, rainfall, wind speed, soil total nitrogen and $\mathrm{PH}$ value, play an important role in crop growth. Appropriate transportation and storage environment determine the quality of produce. Through informationize the environmental factors collected by sensors, the crops' environmental conditions can be perceived directly so as to accumulate the essential environment data for the traceability system for agro-food quality. With the introduction and continuous improvement of the Wireless Sensor Network (WSN) technology, an Ad Hoc Network System is formed in wireless mode. All sensors are worked with each other, and perception, acquisition and processing, which make the monitoring of environmental factors for crops and produce more efficient, energy saving, safety and eco-friendly[17].

\subsection{Data Transmission Technology}

The data transmission technology is the bridge to link all of produce traceability information from scattered individual famers, collective farms, processing firms, transport firms and dealerships. The data transmission technology contains short-distance transmission technology and long-distance transmission technology. Short-distance transmission technologies, which include Bluetooth, ZigBee and Infrared, have the features of handy transport, lower cost and higher safety despite its inconspicuous transfer rate. The long-distance transmission technology contains GSM technology, GPRS technology and $3 \mathrm{G}$ technology that features longer transmission range and faster transmission rate. On the other hand, they have relatively high cost. Therefore, the long-distance transmission technology is fit for data collection and sharing with long distance places. All of these transmission technologies providing a better basis of data exchange for the agro-food traceability system.

\subsection{Geoscience Information Technology}

At present, the technologies of Geographic Information System (GIS) and the General Purpose Radar (GPS) have been widely used in the fields of industry, agriculture, transportation and architecture. GIS refers to the computer system for collection, storage, query, analysis and representation of geography spatial data. It has a top ability in synthetically analysis to administrate the spatial data. GPS can be used as accurately 
positioning for field information and operation equipment. Moreover, combining with the different distribution of the elements in soil, GPS can assist with irrigation, fertilization, spraying, weeding in agricultural filed operation [18].

\section{Application of Information Technology on the Traceability System of Agro-Food Safety and Quality}

To ensure the customers' interests, the agro-food traceability system is designed to effectively pinpoint the source of the produce safety accidents with the help of the original records of the faulty products and deal with those faulty products in time in the case of a problem on the agro-food quality and safety. In recent years, the related scholars and research institutes take some particular produces as the major study objects to explore and research the traceability system of agro-food quality and safety with advanced information technology.

\subsection{Application of Information Technology on Tracking of livestock safety and quality}

In abroad, Fröschle et al. [19] had study on the barcode of readability and optimal print position. In the study, some barcodes were printed on the livestock's mouths and legs with inkjet, then scanning the barcodes to get information, and finally obtained the optimal printing and reading location through statistical analysis. Tomeš et al. [20] proposed a RFID system combined with biological traceability databases-'RFID -Biotrack database system" which kept a lot of livestock's' ID information in each RFID label. Through this ID information, the original of the animal products could be recognized accurately. Farag Sallabi et al. [21] designed and constructed a digital document system for livestock production process based on mobile electronics. The system was divided into four sections: front-end process subsystem; data transmission subsystem; background process subsystem and application administration subsystem. By using the handheld devices like cell phones and PDAs, the production process of the livestock could be logged concisely and precisely. The collected data would be transmitted in real time to the database system with wireless network in order to track down the specific source rapidly by means of the E-documents of production history during the avian disease outbreak.

In China, synthesizing animal identification technology, GPRS technology and 3G technology, Xiong et al. [22-23] developed pork traceability system with PDA that served as the reader device. The system established the electronic files in pig breeding process, and the detailed information of pock data could be queried. At present the system had been applied widely in Tianjin city. Based on the analysis of the key information in breeding beef cattle, Kanget al. [24] developed the PDA-based traceability system for beef cattle quality and safety in feeding process. The data source of the system consists of both the fattening processing information collected by PDA and the feeding information collected by PC. In view of existence question in meats sales-term, Renet al. [25] constructed the meat-productions traceability system by using of RFID technology, EPC technology, GIS technology and IOT technology. The application of the system facilitates the quality and safety tracing in meat-products sales. Panget al. [26] united with RFID technology and WSN technology designing a scheme of acquisition and transmission for dairy traceability information. Furthermore, the reader module had been developed to achieve information convergence for the data fusion problem of the RFID device and WSN device.

\subsection{Application of Information Technology on Tracking of Fisheries Safety and Quality}

In abroad, K Seineet al. [27] came up with a construction method for the traceability system of marine products by use of QR code and Internet. In this system, the marine products would be coded with a unique ID number and saved the ID number into database, and then the paper or plastic label that printed with QR code would be covered 
directly on the marine products. The producers, distributors and retailers could record the fishery operation activities respectively via the Internet, and the customers would acquire the historical information of the relevant marine products by scanning the QR code of the products with their cell phones. Thompsonet al. [28] proposed a traceability solution for marine products based on ERP model. In this case, using EDI and ODBC as the basis of data interchange, and portable data collector, label reading device, RFID device, electronic scale, fish classifier, timer and thermometer as tools, the traceability system of seafood had been discussed. Thakuret al. [29] conducted a method study for building the traceability system model of the frozen mackerel which took the framework agreement of EPCIS as the basis and UML state diagram as a tool.

In China, based on TTT (Temperature, Time, Tolerance) theoretical model, Zhang et al. [30] unite with RFID technology, GPRS technology and mobile technology, and developed the traceability system of frozen tilapia with thermal management method. The refrigerated storage temperature of the frozen tilapia in the cold chain could be real-time monitoring. And the information technology, such as RF wireless communication, GPRS, database and multimedia, could be used to provide the remote support for the monitoring management of tilapia cold-chain. Through query the traceability system, the customers could easily get the temperature information in the tilapia cold-chain. Ren et al. [31] unite with the key point of the ACCP system and the practical experience, analyzed the tilapia breeding process and the essential information of the process, and the web-based traceability system had been structured with .NET platform for the tilapia breeding quality and safety. The system could effectively monitor the key link that impacts the tilapia quality, and provided an appropriate operating platform to control the quality and safety in tilapia breeding management. Qi et al. [32] developed a traceability system for recirculation aquaculture by means of wireless sensor network. In the system layer of remote monitoring, the environmental and operation data collected by WSN and RFID, and entered those data with WLAN into the database in the data service layer. By using the visualized desktop and GUI, the users of the client application layer could easily get the information about aquaculture field in order to exchange information among fisheries managers, breeders and consumers. Yang et al.[33], using USB Key as the basis and QR code as the traceability information carrier of the aquatic product, constructed an aquatic product supervisory system with embedded technology and .NET technology targeted at the enterprise certificate authority. The system implemented a new approach of the effective administration between fishery firms and government agencies.

\subsection{Application of Information Technology on Tracking of Fresh Products Safety and Quality}

In abroad, Arima et al. [34] took strawberry as the study object, and designed acquisition system with robotics and traceability technology for tracing the information in the process of crop production. The system through automatic logging the strawberry's production information with versatile robots in the links of spraying, harvest and classification, and took this production information as the source data of traceability information. Hertog et al. [35] took the Belgium tomato as the study object, and gathered the tomato's temperature information from the planting process to the sales process by using the RFID label which integrated temperature sensors. A quality changed model of the tomato would be made based on the temperature information in order that the users could identify the origin of tomatoes with RFID label and the quality change model. Porto et al. [36] proposed a design method of the computer-based information systems for certified plant traceability by analyzing the production process and specifications of the citrus nursery. This system was considered to be the ideal tool to curb the diffusion of the plant diseases in citrus nursery supply chain. 
In China, Yang et al. [37-38], united with the Extensive Markup language and the traceability data model of the vegetables from the aspect of information technology, constructed the Vegetables Traceability Information Markup Language (VTML) and designed the Schema model of the VTML, which enabled seamless traceability information exchange. Moreover, a safe production and quality traceability system for vegetable had been developed with database technology, network technology, product coding technology and early-warning technology. Li et al. [39] took fresh cucumbers as the study object, designed the record-keeping and decision-support system for traceability in cucumber production by utilized PDA device decision support system and geographic information system. The agricultural activities would be better guided by use of the fertilizing reference model and pest warning system. By analyzed the agricultural operations in mango production and mobile capture technology, Liu et al. [40] united with the PDA capture technique and $\mathrm{QR}$ code label technique to design a mobile collection system for traceability information, and applied this system to the export system of the Taiwan mango. Based on the original geography codes as index and the production information, Deng et al. [41] constructed a system for safe producing management and product tracking of fresh vegetables with Flex technique, Web GIS technique and Web Services technique, and realized the tracking from the production base to the consumers.

\subsection{Application of Information Technology on tracking of Other Produces Safety and Quality}

In abroad, Pérez-Aloe et al. [42] discussed the performances of various electronic labels in different environment in cheese traceability. Papetti et al. [43] took cheese as the study objects as well, proposed an electronic traceability system for nondestructive quality analysis. Serrano et al. [44] discussed how to use the data of the GIS as references to enhance the efficiency of traceability control for high quality honey, and a web geographical information system had been developed apply to script multiple features. Thakur et al. [45] proposed a relational database model that was used for internal traceability for grain management. The grain relational database model had been designed, which includes necessary basis information such as product information and quality characteristics, circulation information, gathering and distribution information and destroy information. The customers would trace back to details in grain circulation by using the system.

In China, $\mathrm{Li}$ et al. [46]united with network technology, GIS technology, GPS technology, universal coding technology to constructed a management information system for bee products traceability by analyzing the factors that influenced the quality and safety of domestic bee products, and realized the forward tracking and reverse tracking for bee products' quality and safety. Zheng et al. [47] took grain and oil products as the object, and studied a hardware terminal for multi-platform traceability. By using of UCC/EAN-128 coding techniques, a traceability platform for the quality and safety of grain and oil products had been constructed with multi-level and multi-role. Zhang et al. [48] gather the information in exploration origin, environment detection and planting process into the data source of traceability in the light of the cultivation standards of pollution-free potato, and a platform system for potato management and traceability had been developed in .NET platform with QR code technology and IOT technology, and realized the traceability barcode remote identifying and querying traceability information.

\section{Problems in Construction of the Traceability System for Agro-Food Safety and Quality with Its Techniques}

\subsection{Lack a Uniform Traceability Information Platform}


Currently, there was lacking a nationwide traceability information platform. The traceability system presents a fragmented state, and the efficient information sharing among systems was not achieved, the diverse traceability systems could track and manage produce just in a given area. In addition, the incompatibility issues among traceability system also had more serious, which could not only cause inconvenience for consumers to query the traceability information of agro-food, but affected the government's demands to supervise the quality and safety of the produce by agro-food traceability system.

\subsection{Rapid Quality-Checking System Needs to be Urgently Developed}

The quality of agricultural products is affected by temperature, humidity, atmospheric environment and soil constituent. Thus, to protect the quality and safety of produce, the relevant studies in sensing technologies are required to be lunched. Meanwhile, the identification technology of low-cost items is one of basic condition in construction of the agro-food traceability system. For adapts to the development demands of agricultural production with scale, precision and installation, the portable hardware systems with good environment adaptability will be researched and developed to rapid detect the produce's quality.

\subsection{Comprehensive Traceability Information is Difficult to Obtain}

Due to a late start of research for agro-food traceability in China, the techniques of package, labeling and traceability are incomplete and the quality management systems are inadequate, which give a rise to the information traceability for agro-food quality just addressed part of the produce safety issues in individual regions. Meantime, since agricultural features in China that decentralized production and independent operation, a situation that separated peasant business have been presented in process of purchase and sale, which makes it hard to uniform the produce's quality and difficult to acquire traceability information.

\section{Conclusions}

It is an effective way for each country in the world to deal with the food safety by means of the quality and safety traceability for agro-food which is an inevitable trend for the world agriculture and food industry with the sound development. In China, the construction of traceability system for agro-food quality and safety is still in the exploratory stage. Compared with western developed countries, in China, the approaches and techniques of traceability are not mature. The management systems in agriculture and food industry need to be perfected. The recognition of the traceability system for agro-food quality and safety is still obviously insufficient for consumer groups. Therefore, as for pushing the traceability system of agro-food quality and safety, the availability of technology, international compatibility, economic affordability and efficiency of reasonable implementation will be taken into account synthetically based on the experience of agro-food traceability in developed countries [49] and a traceability system of quality and safety for agro-food need be studied according with national situations. Meanwhile, the laws and regulations of produce and food must be enacted and improved to further constrains and regulates the market orders of agricultural products.

\section{References}

1. Petter.O, Melania.B: How to define traceability.Trends in Food Science \& Technology 29,142-150(2013)

2. Zhang, H.L., Sun, X.D., Liu, Y.D., et al.: Research on the Feedback System for Quality and Safety of Agricultural Products. Hubei Agricultural Sciences 49(12), 3220-3223(2010).

3. F.Schwagele.: Traceability from European perspective. Meat Science, 71(1): 164-173(2005). 
4. A.Mousavi, M.Sarhadi, and A.Lenk, et al.: Tracing and traceability in the meat processing industry: a solution. British Food Journal 104(1), 7-19 (2002).

5. M. Bertolini, M. Bevilacqua, R. Massini, et al.: FMECA approach to product traceability in the food industry. Food Control 17(2), 137-145(2006).

6. Wang, J.Z.: Existing Problems and Countermeasures for Emergency Treatment of Agricultural Product Quality Safety Accident at Domestic. Journal of Anhui Agricultural Sciences 41(6), 2680-2682(2013).

7. Babot, D., et al.: Comparison of visual and electronic identification devices in pigs: On-farm performances. Journal of Animal Science 9(84), 2575-2581(2006).

8. Xíng, W.Y.: System Construction of the Agricultural Products Traceability in U.S. World Agriculture 4(324), 39-41(2006).

9. G.C. Smith, J.D. Tatum, K.E. Belk, et al.: Traceability from a US perspective. Meat Science 71(1), 174-193(2005).

10. Gao, Y.S., Huan, P., and Hu, and D.G., et al.: Interpret and Appraise of the US FDA Food Safety Modernization Act. Journal of Inspection and Quarantine 21(3), 71-76(2011).

11. Zhao, R., Chen, S., Qiao, J.: Tracing and Supervision System of Food Quality and Safety of America, EU and Japan and the Relevance to China. World Agriculture 3, 1-4 (2012).

12. Wu, M.Y., Song, Y., Ma, C. et al.: 2012 Fruit processing industry development report. China Fruit \& Vegetable 2, 3-5(2013).

13. Fang, R.J.: Study on different stakeholders' transition behaviors and supervisory system in food quality and safety traceable information. Shenyang Agricultural University (2012).

14. Lu, J.H., Guan, J.F., Min, .W.J.: A Tracing System Based on One-dimensional Electronic Code for Quality Safety of Green Fruits. Science \& Technology Review 21, 59-62(2010).

15. Fang, Z.K., Sun, M., Zhao, F.: Two-Dimensional Barcode Technology and Recent Applications on Agriculture Production Quality Traceability System. Conference of CSAE 2009.

16.Li,J., Ma,M.Y., Qin,X.Y., et al.: Research and advances in quality safety control and traceability technology for animal products. Transactions of the CSAE 24(Supp.2), 337-342(2008).
17.Yao,S.F., Feng,C.G.,He,Y.Y., et al.: Application of IOT in Agriculture 33(7), 190-193(2011).

18.Li,D.L.: Introduction to Internet of Things in Agriculture. Science Press, China (2012).

19.Fröschle,H.-K., et al.: Investigation of the potential use of e-tracking and tracing of poultry using linear and 2D barcodes. Computers and Electronics in Agriculture 66(2), 126-132(2009).

20.Tomeš,J., Lukešová,D., Machá,J.: Meat traceability from farm to slaughter using global standards and RFID. Agricultura Tropica et Subtropica 42(3), 98-100(2009).

21.Sallabi, Farag, et al.:Design and implementation of an electronic mobile poultry production documentation system. Computers and Electronics in Agriculture 76(1), 28-37(2011).

22.Xiong,B.H.:A solution on pork quality traceability from farm to dinner table in Tianjin city, China. Agricultural Sciences in China 9(1), 147-156(2010).

23.Xiong,B.H., Luo,Q.Y., Yang,L.,et al.: Development on mobile traceability system of feeding process of pigs and quality safety of its meat products based on 3G technology. Transactions of the Chinese Society of Agricultural Engineering 28(15), 228-233(2012).

24.Kang,R.J., Fu, Z.T. Tian, D., et al.: Design and implementation of beef cattle breeding traceability system based on PDA. Microcomputer Information 5, 50-52(2010).

25.Ren,S.G., Xu, H.L., Li, A., et al.: Meat-productions tracking and traceability system based on internet of things with RFID and GIS. Transactions of the CSAE 26(10), 229-235(2010)

26.Pang,C., He,D.J., Li,C.Y.,et al.: Method of traceability information acquisition and transmission for dairy cattle based on integrating of RFID and WSN. Transactions of the CSAE 27(9), 147-152(2011).

27.Seine, K., et al.:Development of the traceability system which secures the safety of fishery products using the QR code and a digital signature. Proc IEEE TECHNO-OCEAN '04, 2004, Nov. 9-12, Kobe, Japan.

28.Thompson, M., Sylvia,G., Morrissey, M. T. :Seafood traceability in the United States: Current trends, system design, and potential applications. Comprehensive Reviews in Food Science and Food Safety 4(1), 1-7(2005).

29.Thakur,Maitri,et al.:Managing food traceability information using EPCIS framework. Journal of Food Engineering 103(4), 417-433(2011). 
30.Zhang,J., et al.:Development of temperature-managed traceability system for frozen and chilled food during storage and transportation. Journal of Food, Agriculture \& Environment 7(3-4), 132-135(2009).

31.REN,X., ZHANG,X.S., MU,W.S., et al.: Design and implementation of tilapia breeding quality safety traceability system based on web. Computer Engineering and Design 30(16), 3883-3890(2009).

32.Qi,L.,et al.: Developing WSN-based traceability system for recirculation aquaculture. Mathematical and Computer Modeling 53(11):2162-2172(2011).

33.Yang,X.T., Wu,T.Sun,C.H., et al.: Design and Application of Aquatic Enterprise Governance Traceability System Based on USB Key 43(8), 128-133(2012).

34.Arima, Seiichi,et al.: Traceability based on multi-operation robot; information from spraying, harvesting and grading operation robot. Advanced Intelligent Mechatronics.AIM 2003. Proceedings. 2003 IEEE/ASME International Conference on. Vol. 2. IEEE, 2003.

35.Hertog,M.L.A.T.M.,et al.:Smart traceability systems to satisfy consumer expectations.Acta Horticulturae $768,407-415(2008)$.

36.Porto,S.M.C., Arcidiacono,C., Cascone,G.:Developing integrated computer-based information systems for certified plant traceability: Case study of Italian citrus-plant nursery chain.Biosystems Engineering 109(2),120-129(2011).

37.Yang,X.T.,Qian,J.P.,Zhao,C.J.et al.: Construct ion of information description language for vegetable traceability based on XML and its application to data exchange. Transactions of the CSAE 23(11), 201-205(2007).

38.Yang,X.T.,Qian,J.P.,Sun,C.H.,et al.: Design and application of safe production and quality traceability system for vegetable. Transactions of the CSAE 24(3), 162-166(2008).

39.Li,M, et al.:A PDA-based record-keeping and decision-support system for traceability in cucumber production. Computers and Electronics in Agriculture 70(1), 69-77(2010).

40.Liu,Y.C.,Hong,M.,Gao,X.L., et al.: Development and Application of Mobile Traceability Data Construction for Agriculture. Proceedings of the 8th Asian Conference for Information Technology in Agriculture and World Conference on Computer in Agriculture Tianmu
Convention Center Taipei City, Taiwan September 3-6, 2012

41.Deng,X.F., Huang,X.H., Ren,Z.Q., et al.:Geocodingbased technology of safety and traceability for fresh vegetables. Acta Agriculturae Zhejiangensis 1,120-124(2012).

42.Perez-Aloe.: Application of RFID tags for the overall traceability of products in cheese industries.RFID Eurasia, 2007 1st Annual. IEEE, 2007.

43.Papetti, Patrizia, et al.:A RFID web-based infotracing system for the artisanal Italian cheese quality traceability.Food Control 27(1),234-241(2012).

44.Serrano,S. :GIS design application for "Sierra Morena Honey" designation of origin.Computers and electronics in agriculture 64(2), 307-317(2008).

45.Thakur,M.,Bobby,J.M.,Charles R.H.: Data modeling to facilitate internal traceability at a grain elevator. Computers and Electronics in Agriculture 75(2), 327-336(2011).

46.Li,S.J.,Zhu,Y.P.,E,Y.,et al. :Status quo of quality safety of bee products and construction of whole-recess traceability system. Transactions of the CSAE 24(2), 293-297(2008).

47.Zheng,H.G.,Liu,S.H.,Meng,H., et al.: Construction of Traceability System for Quality Safety of Cereal and Oil Products.Scientia Agricultura Sinica 42(9), 3243-3249(2009).

48.Zhang,J.T., Liu,X.,Shi,Z.:Design and Application of Potatoes Safety Management and Traceability Information System. Agriculture Network Information 12, 46-48(2011). 49.Wang,L.F.,Lu,C.H.,Xie,J.F., et al.: Review of traceability system for domestic animals and livestock products. Transactions of the CSAE 21(7), 168-174(2005). 